\title{
Respiratory Therapy Organizational Changes Are Associated With Increased Respiratory Care Utilization
}

\author{
Ann M Parker MD, Xinggang Liu MD, Anthony D Harris MD MPH, Carl B Shanholtz MD, \\ Robin L Smith RRT, Dean R Hess PhD RRT FAARC, \\ Marty Reynolds, and Giora Netzer MD MSCE
}

\begin{abstract}
BACKGROUND: The effect of the respiratory therapist (RT)/patient ratio and RT organizational factors on respiratory resource utilization is unknown. We describe the impact of a multi-component intervention that called for an increase in RT/patient ratio (1:14 to 1:10), improved RT orientation, and formation of a core staffing model on best practice, including spontaneous breathing trials (SBTs) and catheter and bronchoscopically directed lower respiratory tract cultures, or bronchoalveolar lavage (BAL), in both ventilated and non-ventilated patients in the ICU. METHODS: We conducted a single center, quasi-experimental study comparing 651 patients with single and first admissions between April 19, 2005 and April 18, 2006 before the RT services reorganization with 1,073 patients with single and first admissions between September 16, 2007 and September 4, 2008. Baseline characteristics were compared, along with SBTs, BAL use, lower respiratory tract cultures, and chest physiotherapy. RESULTS: Patients in the 2 groups were similar in terms of age $(52.9 \pm 15.8 \mathrm{y}$ vs $53.9 \pm 16.4 \mathrm{y}, P=.23)$, comorbidity as measured by Charlson score $(2.8 \pm 2.6$ vs $2.8 \pm 2.7, P=.56)$, and acuity of illness as measured by the Case Mix Index $(3.2 \pm 3.9$ vs $3.3 \pm 4.1, P=.47)$. Mechanically ventilated patients had similar prevalences of respiratory diseases $(24.2 \%$ vs $25.1 \%, P=.61)$. There was an increase in SBTs $(0.5 \%$ vs $\mathbf{7 3 . 1 \%}$, $P<.001)$, chest physiotherapy $(7.4 \%$ vs $21.6 \%, P<.001)$, BALs $(24.0 \%$ vs $41.4 \%, P<.001)$, and lower respiratory tract cultures $(21.5 \%$ vs $38.0 \%, P<.001)$ in mechanically ventilated patients post-intervention. CONCLUSIONS: A multi-component intervention, including an increase in RT/ patient ratio, improved RT orientation, and establishment of a core staffing model, was associated with increased respiratory resource utilization and evidence-based practice, specifically BALs and SBTs. Key words: personnel staffing and scheduling; critical care; respiratory care units; mechanical ventilators; health resources; work load. [Respir Care 2013;58(3):438-449. (C) 2013 Daedalus Enterprises]
\end{abstract}

\section{Introduction}

One of the defining characteristics of medical critical care is the demand for respiratory care services and the care of patients with respiratory failure. Respiratory care, particularly of mechanically ventilated patients, is respon-

\footnotetext{
Dr Parker is affiliated with the Division of Pulmonary and Critical Care Medicine, Johns Hopkins University; Drs Liu, Harris, and Netzer are affiliated with the Department of Epidemiology and Public Health; and Drs Shanholtz and Netzer are affiliated with the Division of Pulmonary and Critical Care Medicine, University of Maryland School of Medicine, Baltimore, Maryland. Mr Smith and Ms Reynolds are affiliated with the Department of Respiratory Care, University of Maryland Medical Center, Baltimore, Maryland. Dr Hess is affiliated with the Department of Respiratory Care and the Department of Anesthesia, Critical Care, and Pain Medicine, Massachusetts General Hospital, and with the Department of Anesthesia, Harvard Medical School, Boston, Massachusetts.
}

sible for a large proportion of resource utilization in the ICU.1,2 Mechanical ventilation is associated with life-

\begin{abstract}
Dr Parker presented a version of this paper at the Chest 2010 Conference, held October 30 through November 4, 2010, in Vancouver, British Columbia, Canada,
\end{abstract}

Editor in Chief Dean Hess was blinded to the peer review of this paper, which was managed by Deputy Editor Richard Branson. Dr Netzer was supported by a National Institutes of Health Clinical Research Career Development Award. Dr Harris was supported by a National Institutes of Health Midcareer Investigator Grant.

Correspondence: Ann M Parker MD, the Division of Pulmonary and Critical Care Medicine, Johns Hopkins University, 1830 E Monument St, Baltimore MD 21205. E-mail: aparke36@jhu.edu.

DOI: $10.4187 /$ respcare. 01562 
threatening complications, including volutrauma, barotrauma, and ventilator-associated pneumonia (VAP). ${ }^{3}$ These complications lead to increased costs and mortality. ${ }^{3,4}$ Not surprisingly, ventilator liberation has been the focus of much research.

Current evidence has demonstrated that protocols and procedures driven by respiratory therapists (RTs) improve outcomes. ${ }^{5}$ RTs are healthcare professionals whose responsibilities include diagnostic evaluation, management, education, assessment, and rehabilitation of patients with diseases of the cardiopulmonary system. ${ }^{6}$ RT-initiated weaning protocols lead to earlier ventilator liberation, compared with physician-directed methods. ${ }^{7-9}$ Current guidelines support the use of lower respiratory tract cultures in the diagnosis of VAP. ${ }^{10}$ Obtaining these cultures typically requires the assistance of RTs for flexible, fiberoptic bronchoscopic bronchoalveolar lavage (B-BAL) or non-bronchoscopic, catheter-directed BAL (N-BAL). While RTs play an important role in the management of mechanically ventilated patients, few studies have aimed to establish an optimal number of RTs per patient (RT/patient ratio) or examine the impact of an improved RT training curriculum on resource utilization. Currently, no well established evidence-based guidelines exist for RT staffing in the ICU. The Society for Critical Care Medicine recommends that "an appropriate number of respiratory therapists with specialized training must be available to the unit at all times." 11

In a prior study evaluating this cohort and utilizing the same data, we found that a multi-component reorganization of medical ICU resources, including changes in RT staffing and orientation, was associated with a reduction in mortality and an increase in 28-day ventilator free days. ${ }^{12}$ The reorganization of respiratory care services included an increase in the RT/patient ratio, improved RT orientation and education, and the formation of a core staffing model. In assessing potential mechanisms for this improvement in outcomes, we hypothesized that this intervention was associated with increased utilization of best-practice procedures, including spontaneous breathing trials (SBTs) and BALs (bronchoscopic and non-bronchoscopic) in both ventilated and non-ventilated patients in the ICU. To our knowledge, we are the first to study the impact of an increase in $\mathrm{RT} /$ patient ratio, improved training curriculum, and formation of a core staffing model on respiratory care resource utilization and evidence-based practices in the ICU.

\section{Methods}

\section{Environment and Intervention}

We conducted a single-center, quasi-experimental study ${ }^{13,14}$ of all patients admitted to the University of Maryland Medical Center medical ICU (MICU) between April 19, 2005, and April 18, 2006 (12 months pre-

\section{QUICK LOOK}

\section{Current knowledge}

The impact of the respiratory therapist-to-patient ratio and organizational factors on respiratory care resource utilization and patient outcomes is unknown. Respiratory therapists can impact patient outcomes with evidence-based practices, including assessments of weaning readiness and implementation of ventilatorassociated pneumonia prevention bundles.

\section{What this paper contributes to our knowledge}

An increase in respiratory therapist-to-patient ratio in the ICU, from 1:14 to $1: 10$, coupled with a core staffing model and intensive orientation program, increased the utilization of daily spontaneous breathing trials, collection of lower respiratory tract cultures for diagnosis of ventilator-associated pneumonia, chest physical therapy, and inhaled nitric oxide. The cumulative impact on patient costs and outcomes was not assessed.

intervention) and September 16, 2007, and September 4, 2008 (12 months post-intervention). The University of Maryland Medical Center is a 745-bed urban teaching hospital. Prior to the intervention there were 705 total beds. These dates reflect one-year periods before and after the staggered implementation of the multi-step intervention, which occurred between April 19, 2006, and September 15, 2006.

Pre-intervention, the RT department was staffed by a combination of University of Maryland Medical Center employees and locum tenens RTs. There were 10 beds in the pre-intervention MICU, and the RT/patient ratio varied between 1:14 and 1:19. The RTs pre-intervention were often responsible for patients in the medical intermediate care unit as well as other ICUs. The multi-component intervention consisted of a physical move to a new, larger MICU, the creation of a core-RT model, and an enhanced RT training program. The decision to expand the ICU was made in response to increased demand for medical critical care and as a part of the move to a new hospital building, and was unrelated to prior clinical performance of the ICU. The rationale for the RT intervention was to provide adequate staffing for the new MICU and to reduce staffing turnover. The new 29-bed MICU is staffed by at least 3 RTs at all times, with a resultant RT/patient ratio of no less than 1:10. The hiring of locum tenens RTs ceased after the move. In addition, the core-RT model was implemented on September 16, 2007. This model requires 3 RTs to be present on both day and night shifts. At least one registered RT (core RT) with a chosen clinical concentration in medical, as opposed to surgical or trauma, intensive 


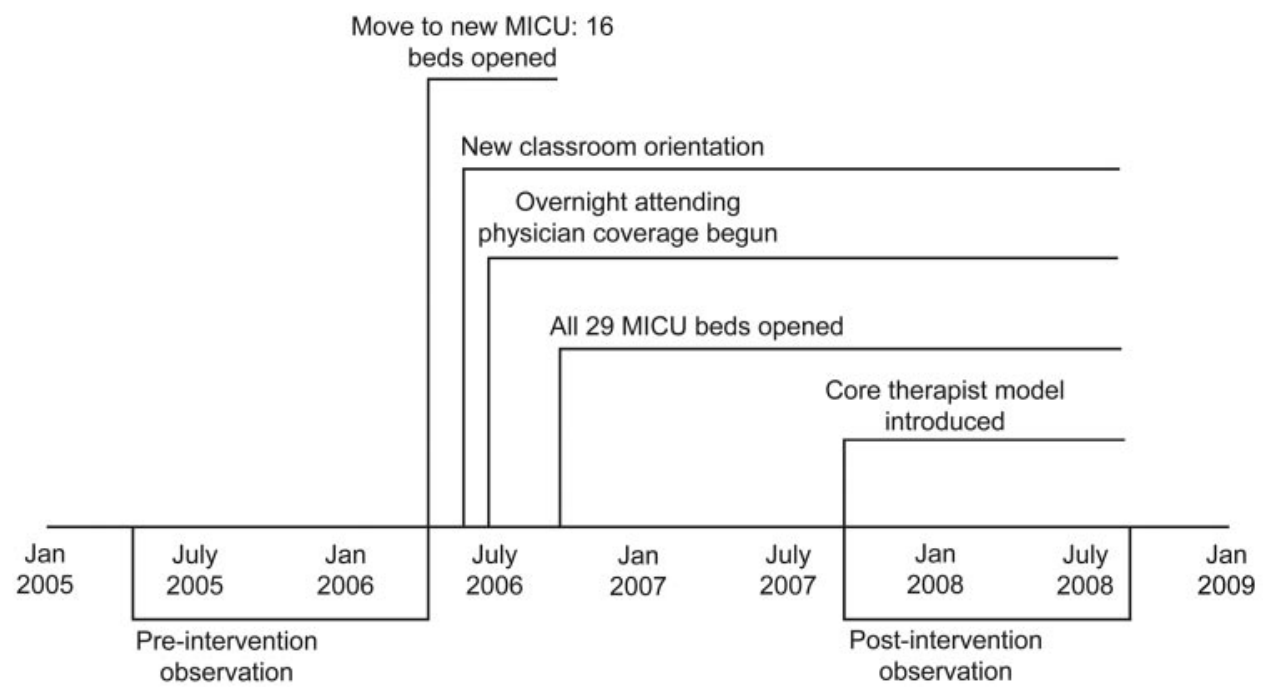

Fig. 1. Timeline of interventions surrounding the move to the new medical ICU (MICU) and reorganization of respiratory care.

care is on the unit at all times. In 2006 the new hire orientation program for RTs was also modified. Prior to this change, orientation included accompanying a veteran RT for several days before working independently. In June 2006 a classroom-style orientation was implemented, consisting of a full-time 4-week lecture series. All procedures and pieces of equipment are reviewed, and a competency exam is conducted after the course. The lectures are taught by a multidisciplinary team comprised of RT clinical coordinators, nurse educators, physicians, and vendors. Following this classroom orientation, the new RTs rotate through 12-hour shifts in more than 3 different ICUs with a preceptor. The new hires are paired with a core RT for the first 6 months. This orientation process occurs $2-3$ times annually, with classes ranging in size from 6 to 19 RTs. There was a change in RT administrators at the time of our intervention. The reorganization of respiratory therapy in the ICU was performed in collaboration with an external consultant (DH).

These changes in respiratory care were part of a multidisciplinary intervention that also included the institution of 24-hour intensivist coverage and the addition of a pharmacist to the multidisciplinary team. ${ }^{15}$ These changes are shown in Figure 1. The RTs' scope of practice, including the procedures performed, did not change. Computerized order reconciliation, including a respiratory care pathway, was implemented after 2006. The medical director of the MICU did not change. In addition to the stability of nursing staffing ratios over this time period, the MICU nursing leadership remained unchanged. There was no change in laboratory, radiology, or consultant services after the intervention, which continued to be fully available 24 hours daily. No changes in protocol or educational campaigns for diagnostic procedures for pneumonia were introduced during the entire study period. Both pre- and post-intervention, B-BALs were obtained by physicians with RT assistance, while N-BALs were performed by RTs, independent of physicians. Similarly, the SBT protocol did not change before or after the intervention, though a computer order reconciliation program was introduced after the intervention.

This study was approved with waiver of consent by the University of Maryland institutional review board.

\section{Data Sources and Patient Selection}

Our primary outcome variables were the number of BBALs, N-BALs, SBTs, upper respiratory tract cultures, and lower respiratory tract cultures. Data were abstracted from the hospital's electronic medical record and administrative record systems, maintained by the Information Technology Group of the University of Maryland Medical Center as a clinical data repository. The clinical data repository is a relational database that has microbiology, pharmacy, admission/discharge/transfer, pathology, and radiology data. The pharmacy, microbiology, and medical demographics tables in the relational database have been regularly validated against medical records in more than 1,400 patients admitted between October 1997 and July 2008. In prior studies, the positive and negative predictive values of random $10 \%$ sampling of the data were $>99 \%$ accurate, when compared to patients' medical charts. ${ }^{16-21}$ A $10 \%$ random sample of the administrative data recording ventilator use found an accuracy rate of $94.1 \%(1,941 /$ 2,062 patient days). Financial data were abstracted from the medical center's administrative data.

We evaluated 3,513 consecutive patients in the 24 months pre-intervention and 24 months post-intervention with first and single admissions on the data file, to protect indepen- 


\section{Respiratory Therapy Organizational Changes}

dence of observations and, to a lesser extent, comparability of the clinical courses studied. Patients missing All Patient Refined Diagnosis-Related Group or International Classification of Diseases, 9th Revision, Clinical Modification codes were excluded from analysis, as were patients with coded negative lengths of stay. We excluded patients admitted during a transition period during which the RT/ patient ratio varied.

\section{Analytic Approach}

We evaluated baseline characteristics of the 2 groups (pre and post intervention), including age, sex, race, percent mechanically ventilated, primary diagnosis, comorbidity as expressed by the Charlson score, and severity of illness as measured by the Case Mix Index weight, a Maryland state measure based on diagnoses and used to adjust hospital reimbursement for expected resource intensity of treatment. (Case Mix Index scores are weighted to a state average of $1.00 .^{22}$ ) The baseline MICU admission characteristics pre- and post-intervention were compared using 2-sample $t$ tests for continuous variables, ${ }^{23}$ and comparisons of proportions for categorical variables. ${ }^{24}$ The total units performed, the proportion of patients receiving them, and the mean number of units per patient before and after intervention were compared with 2sample $t$ tests and Mann-Whitney tests. ${ }^{25}$

RT services utilization was evaluated among all patients meeting study criteria. The following services were identified a priori for analysis: BAL (bronchoscopic and catheter-directed), lower respiratory tract cultures, nasal washings, mechanical and manual chest physiotherapy, incentive spirometry, SBTs, endotracheal tube/tracheostomy care, arterial blood gas sampling, vital capacity, noninvasive ventilation, nebulizers/inhalers, and inhaled nitric oxide. Because mechanically ventilated patients have greater respiratory therapy needs, we performed additional analyses of patients who received one or more days of mechanical ventilation, and patients who did not receive mechanical ventilation, to determine if there was a difference in resource utilization between the 2 groups postintervention. In order to control for changes in the incidence of VAP when examining BALs, N-BALs, and culture data, the proportion of patients with any respiratory culture (both upper and lower) was examined pre- and postintervention. Analyses were performed using statistics software (SAS 9.1.3, SAS Institute, Cary, North Carolina). We applied the traditional definition $(P \leq .05)$ of statistical significance. ${ }^{26}$

\section{Results}

There were 651 patients pre-intervention and 1,073 patients post-intervention for analysis (Fig. 2). Thirty patients were excluded for missing All Patient Refined

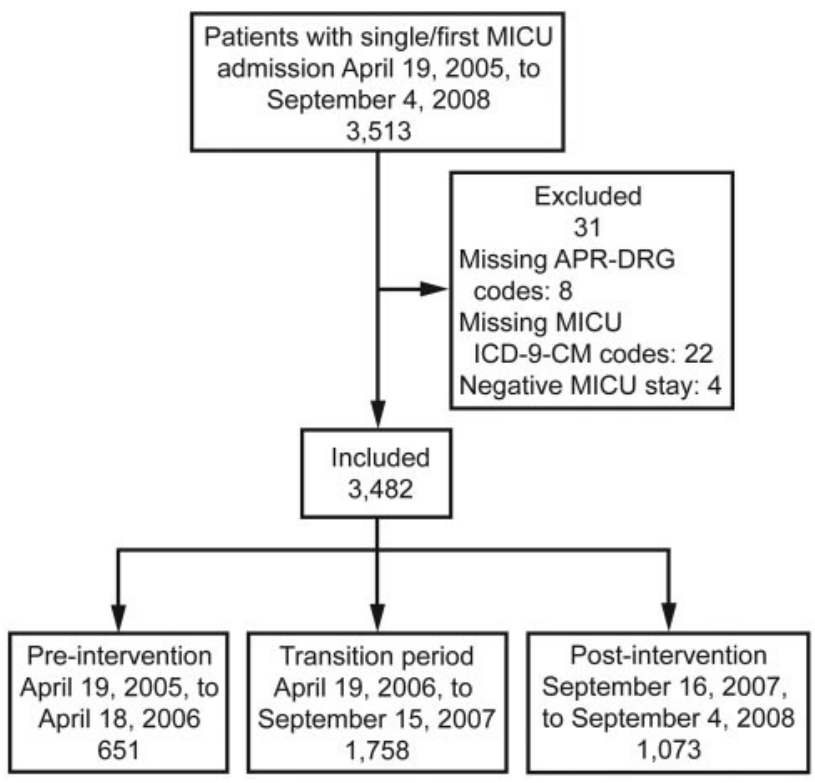

Fig. 2. Enrollment of study participants. MICU = medical ICU APR-DRG = All Patient Refined Diagnosis-Related Group. ICD-9CM International Classification of Diseases, 9th Revision, Clinical Modification.

Diagnosis-Related Group codes and International Classification of Diseases, 9th Revision codes. Patients admitted after the intervention were similar to those admitted preintervention (Table 1). There were no differences in age, sex, race, proportion of patients receiving one or more days of mechanical ventilation, comorbidity as assessed by the Charlson score, or acuity of illness as assessed by the Case Mix Index score. There were no significant changes in the primary diagnoses of patients, though there was a small increase in circulatory-related and neoplasm admissions and corresponding modest declines in the relative incidence of other diagnoses. After the intervention there was an increase in the number of procedures and the proportion of patients undergoing B-BAL, N-BAL, diagnostic nasopharyngeal washing, chest physiotherapy, and incentive spirometry (Table 2, Fig. 3).

Among patients receiving one or more days of mechanical ventilation, there were no differences in age, sex, race, Charlson score, Case Mix Index weight, or primary diagnosis (see Table 1). A greater proportion of these patients received chest physiotherapy, incentive spirometry, endotracheal tube or tracheostomy care, arterial blood gas puncture, SBTs, nitric oxide therapy and measurement of vital capacity (Table 3, Fig. 4). The proportion of patients undergoing lower respiratory tract diagnostic procedures (ie, $\mathrm{B}-\mathrm{BAL}$ or N-BAL) and the number of procedures per patient increased after the intervention (Fig. 5). In order to demonstrate that this increase was not due to an increased incidence of VAP or suspected VAP, the proportion of patients with any respiratory culture (both upper and 


\section{Respiratory Therapy Organizational Changes}

Table 1. Subject Characteristics

\begin{tabular}{|c|c|c|c|}
\hline & $\begin{array}{l}\text { Pre-intervention } \\
\quad(n=651)\end{array}$ & $\begin{array}{l}\text { Post-intervention } \\
\quad(n=1,073)\end{array}$ & $P^{*}$ \\
\hline \multicolumn{4}{|l|}{ Mechanical Ventilation } \\
\hline Non-ventilated & $325(49.9)$ & $578(53.9)$ & .11 \\
\hline Ventilated & $326(50.1)$ & $495(46.1)$ & \\
\hline \multicolumn{4}{|l|}{ Age, mean $\pm \mathrm{SD}$} \\
\hline All patients & $52.9 \pm 15.8$ & $53.9 \pm 16.4$ & .23 \\
\hline Non-ventilated & $51.1 \pm 16.2$ & $52.4 \pm 16.8$ & .25 \\
\hline Ventilated & $54.7 \pm 15.3$ & $55.5 \pm 15.8$ & .43 \\
\hline \multicolumn{4}{|l|}{ Male } \\
\hline All patients & $291(44.7)$ & $465(43.3)$ & .58 \\
\hline Non-ventilated & $154(47.4)$ & $256(44.3)$ & .37 \\
\hline Ventilated & $137(42.0)$ & $209(42.2)$ & .96 \\
\hline \multicolumn{4}{|l|}{ Race Non-white } \\
\hline All patients & $374(57.5)$ & $589(54.9)$ & .30 \\
\hline Non-ventilated & $188(57.9)$ & $328(56.8)$ & .75 \\
\hline Ventilated & $186(57.1)$ & $261(52.7)$ & .22 \\
\hline \multicolumn{4}{|l|}{ MICU Charlson Score, mean \pm SD } \\
\hline All patients & $2.8 \pm 2.6$ & $2.8 \pm 2.7$ & .56 \\
\hline Non-ventilated & $2.9 \pm 2.7$ & $2.8 \pm 2.7$ & .70 \\
\hline Ventilated & $2.7 \pm 2.6$ & $2.9 \pm 2.7$ & .21 \\
\hline \multicolumn{4}{|l|}{ Case Mix Index Score, mean \pm SD } \\
\hline All patients & $3.2 \pm 3.9$ & $3.3 \pm 4.1$ & .47 \\
\hline Non-ventilated & $2.0 \pm 1.8$ & $2.2 \pm 3.2$ & .12 \\
\hline Ventilated & $4.3 \pm 4.9$ & $4.5 \pm 4.6$ & .53 \\
\hline \multicolumn{4}{|l|}{ MICU Primary Diagnosis } \\
\hline \multicolumn{4}{|l|}{ All patients } \\
\hline Disease of the respiratory system & $134(20.6)$ & $195(18.2)$ & .051 \\
\hline Disease of the circulatory system & 84 (12.9) & $197(18.4)$ & \\
\hline Disease of the digestive system & $74(11.4)$ & $120(11.2)$ & \\
\hline Infectious and parasitic disease & $95(14.6)$ & $144(13.4)$ & \\
\hline Injury and poisoning & $64(9.8)$ & $96(9.0)$ & \\
\hline Neoplasm & $51(7.8)$ & $105(9.8)$ & \\
\hline Other & $149(22.9)$ & $216(20.1)$ & \\
\hline \multicolumn{4}{|l|}{ Non-ventilated } \\
\hline Disease of the respiratory system & $55(16.9)$ & $71(12.3)$ & .01 \\
\hline Disease of the circulatory system & $45(13.9)$ & $124(21.5)$ & \\
\hline Disease of the digestive system & $48(14.8)$ & $74(12.8)$ & \\
\hline Infectious and parasitic disease & $32(9.9)$ & $42(7.3)$ & \\
\hline Injury and poisoning & $36(11.1)$ & $60(10.4)$ & \\
\hline Neoplasm & $23(7.1)$ & $65(11.3)$ & \\
\hline Other & $86(26.5)$ & $142(24.6)$ & \\
\hline \multicolumn{4}{|l|}{ Ventilated } \\
\hline Disease of the respiratory system & $79(24.2)$ & $124(25.1)$ & .61 \\
\hline Disease of the circulatory system & $39(12.0)$ & $73(14.8)$ & \\
\hline Disease of the digestive system & $26(8.0)$ & $46(9.3)$ & \\
\hline Infectious and parasitic disease & $63(19.3)$ & $102(20.6)$ & \\
\hline Injury and poisoning & $28(8.6)$ & $36(7.3)$ & \\
\hline Neoplasm & $28(8.6)$ & $40(8.1)$ & \\
\hline Other & $63(19.3)$ & $74(15.0)$ & \\
\hline
\end{tabular}


Table 2. Respiratory Therapy Use in All Patients

\begin{tabular}{|c|c|c|c|}
\hline & $\begin{array}{l}\text { Pre-intervention } \\
\quad(n=651)\end{array}$ & $\begin{array}{l}\text { Post-intervention } \\
\quad(n=1,073)\end{array}$ & $P^{*}$ \\
\hline \multicolumn{4}{|l|}{ Nebulizer/Inhaler } \\
\hline$\%$ used & $276(42.4)$ & 437 (40.7) & .50 \\
\hline Units per MICU day & $1.7 \pm 2.5$ & $1.4 \pm 2.2$ & .06 \\
\hline \multicolumn{4}{|l|}{ B-BAL and N-BAL } \\
\hline$\%$ used & $91(14.0)$ & $226(21.1)$ & $<.001$ \\
\hline Units per MICU day & $0.0 \pm 0.1$ & $0.1 \pm 0.4$ & $<.001$ \\
\hline \multicolumn{4}{|c|}{ Upper Respiratory Tract Cultures } \\
\hline$\%$ used & $233(35.8)$ & $384(35.8)$ & $>.99$ \\
\hline Units per MICU day & $0.1 \pm 0.2$ & $0.2 \pm 0.3$ & .10 \\
\hline \multicolumn{4}{|l|}{ Arterial Blood Gas } \\
\hline$\%$ used & $271(41.6)$ & $497(46.3)$ & .058 \\
\hline Units per MICU day & $0.3 \pm 0.5$ & $0.2 \pm 0.4$ & .54 \\
\hline \multicolumn{4}{|c|}{ Nasal Wash (for respiratory viruses) } \\
\hline$\%$ used & $35(5.4)$ & 138 (12.9) & $<.001$ \\
\hline Units per MICU day & $0.0 \pm 0.1$ & $0.0 \pm 0.2$ & $<.001$ \\
\hline \multicolumn{4}{|c|}{ Manual Chest Physiotherapy } \\
\hline$\%$ used & $29(4.5)$ & $110(10.3)$ & $<.001$ \\
\hline Units per MICU day & $0.1 \pm 0.4$ & $0.1 \pm 0.5$ & $<.001$ \\
\hline \multicolumn{4}{|l|}{ Incentive Spirometry } \\
\hline$\%$ used & $8(1.2)$ & $40(3.7)$ & .002 \\
\hline Units per MICU day & $0.0 \pm 0.1$ & $0.0 \pm 0.1$ & .002 \\
\hline \multicolumn{4}{|l|}{ Noninvasive Ventilation } \\
\hline$\%$ used & $65(10.0)$ & $113(10.5)$ & .72 \\
\hline Units per MICU day & $0.0 \pm 0.1$ & $0.0 \pm 0.2$ & .71 \\
\hline \multicolumn{4}{|c|}{$\begin{array}{l}\text { The \% used values are no. (\%). The units per medical ICU (MICU) day are mean } \pm \text { SD, based on stay in integer days. } \\
* P \text { values were obtained from tests of comparison of proportions and 2-sample non-parametric Mann-Whitney tests. } \\
\text { B-BAL = bronchoscopic bronchoalveolar lavage } \\
\text { N-BAL }=\text { non-bronchoscopic, catheter-directed bronchoalveolar lavage }\end{array}$} \\
\hline
\end{tabular}

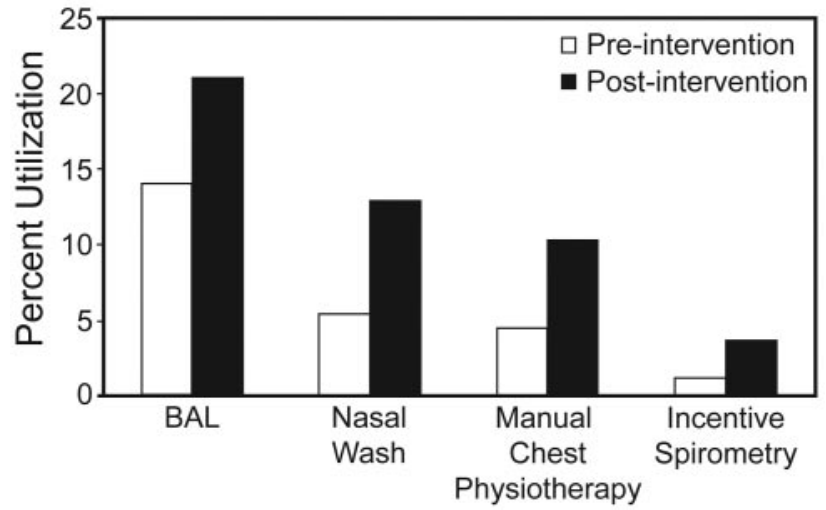

Fig. 3. Percent respiratory therapy resource utilization in all patients (mechanically ventilated and non-ventilated) pre- and postintervention. BAL = both bronchoscopic and non-bronchoscopic, catheter-directed BAL. Nasal wash = nasal sampling for respiratory viruses.

lower) was used as a control and examined pre- and postintervention. The proportion of lower respiratory tract cultures to total respiratory cultures was assessed for pre- and post-intervention patients. Post-intervention, an increased proportion of patients underwent lower respiratory tract diagnostic procedures (24.0\% pre-intervention vs $41.4 \%$ post-intervention, $P<.001)$ and had lower respiratory tract specimens obtained $(21.5 \%$ vs $38.0 \%, P<.001)$. The proportion of respiratory cultures that were obtained from the lower respiratory tree increased after the intervention $(18.6 \pm 30.9 \%$ vs $30.1 \pm 34.3 \%, P<.001)$. There was no difference in the proportion of patients undergoing upper respiratory tract cultures before and after the intervention (59.5\% vs $63.4 \%, P=.26)$.

Among patients who were never mechanically ventilated, there were no differences between the pre- and postintervention groups with regards to age, race, sex, comorbidity as measured by the Charlson Score, or illness severity as demonstrated by the Case Mix Index (see Table 1). There were significant differences between the 2 groups in terms of MICU primary diagnosis $(P=.01)$. There were no differences in respiratory therapy resource utilization between non-ventilated patients before and after the intervention with regards to: nebulizers, B-BALs, upper respiratory tract cultures, nasal washings, mechanical chest physiotherapy, incentive spirometry, and noninvasive mechanical ventilation (Table 4). A greater proportion of patients who were never mechanically ventilated had arterial 


\section{Respiratory Therapy Organizational Changes}

Table 3. Respiratory Therapy Use in Mechanically Ventilated Patients

\begin{tabular}{|c|c|c|c|}
\hline & $\begin{array}{l}\text { Pre-intervention } \\
\quad(n=326)\end{array}$ & $\begin{array}{l}\text { Post-intervention } \\
\quad(n=495)\end{array}$ & $P^{*}$ \\
\hline \multicolumn{4}{|l|}{ Spontaneous Breathing Trials } \\
\hline$\%$ used & $31(0.5)$ & $362(73.1)$ & $<.001$ \\
\hline Units per ventilated day & $0.0 \pm 0.1$ & $0.5 \pm 0.5$ & $<.001$ \\
\hline \multicolumn{4}{|l|}{ Vital Capacity } \\
\hline$\%$ used & $6(1.8)$ & $44(8.9)$ & \multirow[t]{2}{*}{$<.001$} \\
\hline Units per ventilated day & $0.0 \pm 0.1$ & $0.0 \pm 0.2$ & \\
\hline \multicolumn{4}{|l|}{ Nebulizer/Continuous Nebulization/MDI } \\
\hline$\%$ used & $203(62.3)$ & $326(65.9)$ & .29 \\
\hline Units per ventilated day & $3.1 \pm 4.0$ & $4.0 \pm 6.5$ & .02 \\
\hline \multicolumn{4}{|l|}{ Nitric Oxide } \\
\hline$\%$ used & $1(0.3)$ & $24(4.9)$ & \multirow[t]{2}{*}{$<.001$} \\
\hline Units per ventilated day & $0.0 \pm 0.0$ & $0.0 \pm 0.1$ & \\
\hline \multicolumn{4}{|l|}{ N-BAL } \\
\hline$\%$ used & $40(12.3)$ & $151(30.5)$ & $<.001$ \\
\hline Units per ventilated day & $0.0 \pm 0.1$ & $0.1 \pm 0.1$ & $<.001$ \\
\hline \multicolumn{4}{|l|}{ B-BAL and N-BAL } \\
\hline$\%$ used & $78(24.0)$ & $205(41.4)$ & $<.001$ \\
\hline Units per ventilated day & $0.0 \pm 0.1$ & $0.2 \pm 0.5$ & $<.001$ \\
\hline \multicolumn{4}{|l|}{ Lower Respiratory Tract Cultures } \\
\hline$\%$ used & $70(21.5)$ & $188(38.0)$ & $<.001$ \\
\hline Units per ventilated day & $0.1 \pm 0.1$ & $0.1 \pm 0.2$ & $<.001$ \\
\hline \multicolumn{4}{|l|}{ Upper Respiratory Tract Cultures } \\
\hline$\%$ used & $194(59.5)$ & $314(63.4)$ & .26 \\
\hline Units per ventilated day & $0.2 \pm 0.3$ & $0.3 \pm 0.4$ & .02 \\
\hline \multicolumn{4}{|l|}{ Total Respiratory Tract Cultures (lower and upper) } \\
\hline$\%$ used & $210(64.4)$ & $354(71.5)$ & .03 \\
\hline Units per ventilated day & $0.2 \pm 0.3$ & $0.4 \pm 0.5$ & $<.001$ \\
\hline $\begin{array}{l}\text { Percent of Respiratory Cultures From Lower Respiratory Tree, } \\
\text { Given at Least One Culture Was Done, mean } \pm \text { SD } \%\end{array}$ & $18.6 \pm 30.9$ & $30.1 \pm 34.3$ & $<.001$ \\
\hline \multicolumn{4}{|l|}{ Arterial Blood Gas Analysis } \\
\hline$\%$ used & $215(66.0)$ & $362(73.1)$ & .03 \\
\hline Units per ventilated day & $0.5 \pm 0.6$ & $0.6 \pm 0.8$ & .12 \\
\hline \multicolumn{4}{|l|}{ Nasal Wash (for respiratory viruses) } \\
\hline$\%$ used & $26(8.0)$ & $116(23.4)$ & $<.001$ \\
\hline Units per ventilated day & $0.0 \pm 0.1$ & $0.1 \pm 0.6$ & $<.001$ \\
\hline \multicolumn{4}{|l|}{ Manual and Mechanical Chest Physiotherapy } \\
\hline$\%$ used & $24(7.4)$ & $107(21.6)$ & $<.001$ \\
\hline Units per ventilated day & $0.1 \pm 0.5$ & $0.4 \pm 1.6$ & $<.001$ \\
\hline \multicolumn{4}{|l|}{ Mechanical Chest Physiotherapy } \\
\hline$\%$ used & $0(0.0)$ & $15(3.0)$ & \\
\hline Units per ventilated day & $0.0 \pm 0.0$ & $0.0 \pm 0.3$ & \\
\hline \multicolumn{4}{|l|}{ Manual Chest Physiotherapy } \\
\hline$\%$ used & $24(7.4)$ & $99(20.0)$ & $<.001$ \\
\hline Units per ventilated day & $0.1 \pm 0.5$ & $0.4 \pm 1.6$ & $<.001$ \\
\hline \multicolumn{4}{|l|}{ Incentive Spirometry } \\
\hline$\%$ used & $7(2.2)$ & $30(6.1)$ & \multirow[t]{2}{*}{$<.008$} \\
\hline Units per ventilated day & $0.0 \pm 0.0$ & $0.0 \pm 0.2$ & \\
\hline \multicolumn{4}{|l|}{ Noninvasive Ventilation } \\
\hline$\%$ used & $51(15.6)$ & $83(16.8)$ & .67 \\
\hline Units per ventilated day & $0.1 \pm 0.2$ & $0.1 \pm 0.4$ & .008 \\
\hline \multicolumn{4}{|l|}{ Endotracheal/Tracheostomy Tube Care } \\
\hline$\%$ used & $139(42.6)$ & $323(65.3)$ & $<.001$ \\
\hline Units per ventilated day & $0.1 \pm 0.2$ & $0.3 \pm 0.4$ & $<.001$ \\
\hline $\begin{array}{l}\text { The } \% \text { used values are no. }(\%) \text {. The units per ventilated day are mean } \pm \mathrm{SD} \text {. } \\
* P \text { values were obtained from tests of comparison of proportions, } 2 \text {-sample non-para } \\
\mathrm{MDI}=\text { metered-dose inhaler } \\
\text { N-BAL }=\text { non-bronchoscopic, catheter-directed bronchoalveolar lavage } \\
\mathrm{B}-\mathrm{BAL}=\text { bronchoscopic bronchoalveolar lavage }\end{array}$ & est, by comparing pre-int & post-intervention. & \\
\hline
\end{tabular}




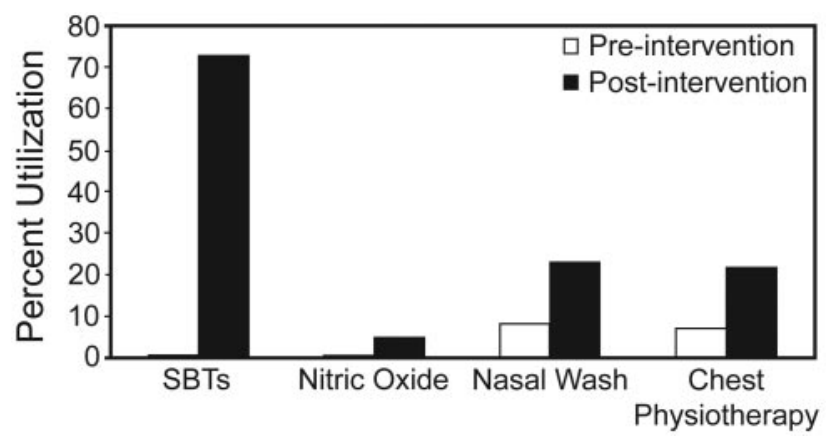

Fig. 4. Percent respiratory therapy resource utilization in mechanically ventilated patients pre- and post-intervention. SBT = spontaneous breathing trial. Nasal wash $=$ nasal sampling for respiratory viruses.

blood gas sampling after the intervention $(17.2 \%$ vs $23.4 \%$, $P=.03)$.

\section{Discussion}

Respiratory care plays a central role in the management of patients with critical illness. Our study found increased utilization of respiratory resources, including B-BALs, N-

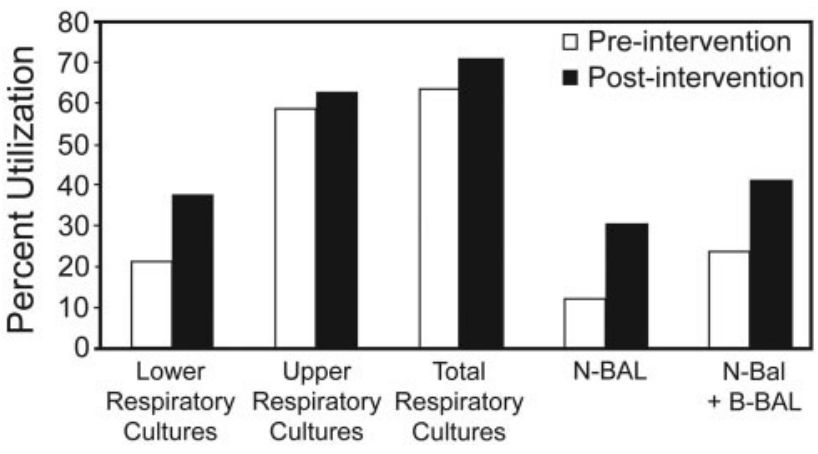

Fig. 5. Percent utilization of respiratory culture resources in mechanically ventilated patients pre- and post-intervention. $\mathrm{N}-\mathrm{BAL}=$ non-bronchoscopic, catheter-directed bronchoalveolar lavage. $\mathrm{B}-\mathrm{BAL}=$ bronchoscopic BAL.

BALs, and SBTs, and greater frequency of evidence-based practices occurred after a multi-component intervention that called for improved RT staffing (including elimination of locum tenens RTs) and orientation. Determination of the degree to which each individual component contributed to the results observed is beyond the scope of this study. To our knowledge, this is the first study to examine

Table 4. Respiratory Therapy Use in Non-ventilated Patients

\begin{tabular}{|c|c|c|c|}
\hline & $\begin{array}{l}\text { Pre-intervention } \\
\quad(n=325)\end{array}$ & $\begin{array}{l}\text { Post-intervention } \\
\quad(n=578)\end{array}$ & $P^{*}$ \\
\hline \multicolumn{4}{|l|}{ Nebulizer/Inhaler } \\
\hline$\%$ used & $73(22.5)$ & $111(19.2)$ & .24 \\
\hline Units per MICU day & $0.9 \pm 2.0$ & $0.5 \pm 1.4$ & .11 \\
\hline \multicolumn{4}{|l|}{ B-BAL } \\
\hline$\%$ used & $13(4.0)$ & $21(3.6)$ & .78 \\
\hline \multicolumn{4}{|l|}{ Units per MICU day } \\
\hline \multicolumn{4}{|c|}{ Upper Respiratory Tract Cultures } \\
\hline$\%$ used & $39(12.0)$ & $70(12.1)$ & .96 \\
\hline Units per MICU day & $0.1 \pm 0.2$ & $0.1 \pm 0.2$ & .78 \\
\hline \multicolumn{4}{|c|}{ Arterial Blood Gas Analysis } \\
\hline$\%$ used & $56(17.2)$ & $135(23.4)$ & .03 \\
\hline Units per MICU day & $0.1 \pm 0.3$ & $0.1 \pm 0.3$ & .03 \\
\hline \multicolumn{4}{|c|}{ Nasal Wash (for respiratory viruses) } \\
\hline$\%$ used & $9(2.8)$ & $22(3.8)$ & .45 \\
\hline Units per MICU day & $0.0 \pm 0.2$ & $0.0 \pm 0.1$ & .41 \\
\hline \multicolumn{4}{|c|}{ Manual Chest Physiotherapy } \\
\hline$\%$ used & $5(1.5)$ & $11(1.9)$ & .80 \\
\hline Units per MICU day & $0.0 \pm 0.3$ & $0.0 \pm 0.3$ & .70 \\
\hline \multicolumn{4}{|l|}{ Incentive Spirometry } \\
\hline$\%$ used & $1(0.3)$ & $10(1.7)$ & .11 \\
\hline Units per MICU day & $0.0 \pm 0.1$ & $0.0 \pm 0.1$ & .06 \\
\hline \multicolumn{4}{|l|}{ Noninvasive Ventilation } \\
\hline$\%$ used & $14(4.3)$ & $30(5.2)$ & .55 \\
\hline Units per MICU day & $0.0 \pm 0.1$ & $0.0 \pm 0.2$ & .58 \\
\hline \multicolumn{4}{|c|}{$\begin{array}{l}\text { The \% used values are no. (\%). The units per medical ICU (MICU) day are mean } \pm \text { SD, based on stay in integer days. } \\
* P \text { values were obtained from tests of comparison of proportions and 2-sample non-parametric Mann-Whitney tests. } \\
\text { B-BAL }=\text { bronchoscopic bronchoalveolar lavage }\end{array}$} \\
\hline
\end{tabular}




\section{Respiratory Therapy Organizational Changes}

respiratory resource utilization and adherence to evidencebased practice after changes in respiratory staffing and orientation. These improvements in care point to a potential mechanism for our prior findings of a reduction in the odds ratio of death by $22 \%$ (95\% CI $0.61-0.99, P=.04$ ) and increased 28-day ventilator-free days (median $21 \mathrm{~d}$ [IQR 0-25 d] vs 22 [IQR 0-26 d], $P=.04$ ) among mechanically ventilated patients after a multi-component intervention.

Currently, no concrete guidelines exist regarding RT staffing ratios. A 2006 study, surveying RTs at 30 hospitals ranging in bed size from $<250$ to $>500$ beds, concluded that increased RT staffing would be necessary if ICUs continued to grow as projected. ${ }^{27} \mathrm{~A}$ recommendation was made that one new RT be hired for every 11.3 beds added to an ICU, in order to maintain appropriate patient care. ${ }^{27}$ Our study found that an improved RT staffing ratio of 1:10 (increased from 1:14) was associated with increased utilization of best-evidence practice in the care of mechanically ventilated patients.

The current literature shows the importance of SBTs in the management of mechanically ventilated patients. Current guidelines recommend the use of SBTs to determine which patients are appropriate for ventilator liberation. ${ }^{28}$ Ventilator liberation protocols that incorporate daily SBTs have been shown to increase ventilator-free days and decrease hospital stay, compared to physician-driven ventilator liberation. ${ }^{29-33}$ Daily SBTs in mechanically ventilated patients lead to decreased duration of ventilation as well as fewer complications, when compared to patients who did not undergo an SBT. ${ }^{29}$ SBTs have also been associated with earlier extubation than trials of pressure support or intermittent mandatory ventilation, ${ }^{34}$ and protocoldriven SBTs increase the extubation rate without a change in reintubation rates, when compared with unregulated ventilator management. ${ }^{33}$ The Awakening and Breathing Controlled Trial showed that protocols pairing interruption of sedation with daily SBTs improved outcomes in ICU patients. ${ }^{35,36}$ While any non-physician healthcare provider was permitted to utilize weaning protocols in many of the above studies, there are several trials showing the same benefit with regard to outcomes when the protocols were implemented by RTs only. ${ }^{7,32}$ At our study institution, SBT protocols are implemented exclusively by RTs. Our study shows that improved RT training and staffing increased adherence to daily SBTs.

This multi-component intervention was associated with increased utilization of lower respiratory tract cultures. While controversy exists regarding the diagnosis and management of VAP, current American Thoracic Society guidelines favor the use of lower respiratory tract cultures in diagnosing and managing VAP. ${ }^{10}$ Lower respiratory tract cultures, when used as part of a clinical scoring system, decrease costs and reduce antibiotic usage in the manage- ment of VAP, ${ }^{37}$ and facilitate early appropriate antibiotic use in patients suspected of having VAP. ${ }^{38}$ A randomized controlled trial demonstrated improved outcomes, including a decrease in mortality and less antibiotic use, when BAL was used as part of the clinical diagnostic criteria for VAP, as opposed to endotracheal aspirates alone. ${ }^{39}$ At our study site, RTs perform catheter-directed BALs and assist with bronchoscopic BALs, which are the preferred methods of obtaining lower respiratory tract cultures. Our study shows an association with improved RT staffing and evidence-based practice in the diagnosis and management of patients with VAP.

RTs are an essential part of the multidisciplinary team. Daily rounds by a multidisciplinary care team are associated with lower mortality..$^{40}$ Implementation of a 24-hour in-house attending is associated with improved outcomes in the ICU. ${ }^{41}$ It is likely that the benefit of increased and reorganized RT staffing in our ICU was maximized by the structure of our MICU, which is characterized by both full multidisciplinary staffing and rounds, and around-the-clock intensivist coverage. For example, while both B-BAL and N-BAL are ordered by physicians, we hypothesize that the availability and collaboration of RTs in patient care facilitated the ordering and completion of these diagnostic procedures.

Given our study's quasi-experimental design, we took care to assess whether or not the increase in lower respiratory tract cultures post-intervention was not due simply to a change in case mix or an increase in the incidence of VAP. We evaluated both the total number of lower respiratory tract cultures obtained, and the proportion of respiratory tract cultures (upper vs lower) as a control. We observed an increase in the total number of cultures occurring after the intervention. Of these, lower respiratory tract cultures accounted for the greater proportion of culture type, consistent with a change in practice independent of possible temporal changes. While no reciprocal decrease in upper respiratory tract culture sampling was found, we are confident that there was an increase in use of lower respiratory tract cultures, which has been shown to improve VAP treatment. Previous analysis of the MICU patient population pre- and post-intervention showed that the case mix remained stable over the entire period studied. ${ }^{12}$

Our study does have certain limitations. Although we found no difference between the 2 groups with regard to illness severity and comorbidities using the Case Mix Index and Charlson score, respectively, and no difference between the 2 groups of mechanically ventilated patients with regard to primary diagnosis, residual confounding may still have occurred, which is possible in quasi-experimental studies. A large proportion of the data assessing ICU staffing, including physician staffing, derives from quasi-experimental or observational studies. ${ }^{41}$ Additional interventions occurred concurrently with the reorganiza- 


\section{Respiratory Therapy Organizational Changes}

tion of respiratory care services. These included the implementation of a 24-hour in-house intensivist and the addition of a clinical pharmacist to the care team. ${ }^{15}$ It is difficult to isolate their relative contribution to the overall change in resource utilization, though we believe that it was the combination of these that maximized the benefit of the RT intervention.

While a clustered randomized trial examining the direct effects of RT staffing in the ICU would be ideal, this may not be feasible. While protocol-directed ventilator liberation was present prior to the intervention, computerized order reconciliation for respiratory care services was implemented after our intervention, which may have also increased adherence to respiratory care protocols. The notably low number of SBTs pre-intervention suggests either difficulties adhering to daily ventilation trial protocols or a lack of documentation, both of which would have been improved by increased RT staffing and improved training. The motivation of the RTs may have increased post-intervention, as locum tenens employees were eliminated and the remaining RTs were therefore considered long-term staff. This is an inherent component of the reorganization of the ICU post-intervention.

While SBTs are considered standard of care with regard to ventilator liberation, and lower respiratory tract culture sampling is best practice in the management of VAP, the benefit of some procedures may be less clear. For example, multiple studies of chest physiotherapy suggest little benefit when it is used in isolation, ${ }^{42-44}$ while the data on incentive spirometry are conflicting. ${ }^{45-47}$ Inhaled nitric oxide is of high cost and has not been shown to provide improvements in outcome. ${ }^{48}$ Thus, in appraising these results, a distinction may be required in parsing the relative benefits of each change in respiratory care delivery, and the reader should consider that analysis of the appropriateness of each procedure in a patient-specific context is beyond the scope of this study.

Expanding the number of RTs available in an ICU requires additional resources for salary support. Additionally, improved orientation requires substantial resources for teaching and training. This includes the extended training interval during which the hospital supports trainees until their completion of classroom instruction and training. We did find that these costs were offset by greater stability in staffing and greater productivity. Review of budget data for full medical center respiratory care services revealed the cost of training new RTs was $\$ 1,000$ per week per RT. Fiscal year 2005 (July 1 through June 30), preintervention, was compared to 2008, post-intervention. In 2005 the budget included 36.47 full-time equivalents (FTEs) of locum tenens RTs, 14.1 FTEs of certified RTs, and 15.8 FTEs of registered RTs. There were 3 FTEs of coordinators, and a 0.9 FTE supervisor. The total 2005 budget was $\$ 5,485,111$ for all staffing and training. In
2008 the budget included 0.83 FTEs of locum tenens RTs, 7.10 FTEs of certified RTs, 73.75 FTEs of registered RTs, 2.70 FTEs of supervisors, 4.88 FTEs of coordinators, and a 1.0 FTE educator. The total 2008 budget for all staffing and training was $\$ 5,569,179$. Relative value units billed increased from 10,087,739 in 2005 to 11,636,577 in 2008. In summary, the relative value units per dollar generated rose from 1.84 pre-intervention to 2.09 post-intervention.

It is our belief that these added costs are justified by increased adherence to evidence-based practice and are cost-effective due to greater efficiency. However, a comprehensive analysis of the cost-effectiveness of this intervention is outside the scope of this study. As a large, tertiary care center, our results may not apply to other settings.

\section{Conclusions}

A multi-component intervention, including an increase in RT/patient ratio, improved RT orientation, and the establishment of a core staffing model was associated with increased respiratory resource utilization and evidencebased respiratory care, specifically SBTs and BALs.

\section{ACKNOWLEDGMENT}

We are grateful to Jeff Ford MHA RRT for his abstraction and analysis of budget data.

\section{REFERENCES}

1. Dasta JF, McLaughlin TP, Mody SH, Piech CT. Daily cost of an intensive care unit day: the contribution of mechanical ventilation. Crit Care Med 2005;33(6):1266-1271

2. Zilberberg MD, Shorr AF. Prolonged acute mechanical ventilation and hospital bed utilization in 2020 in the United States: implications for budgets, plant and personnel planning. BMC Health Serv Res 2008;8:242

3. Sandur S, Stoller JK. Pulmonary complications of mechanical ventilation. Clin Chest Med 1999;20(2):223-247.

4. Warren DK, Shukla SJ, Olsen MA, Kollef MH, Hollenbeak CS, Cox $\mathrm{MJ}$, et al. Outcome and attributable cost of ventilator-associated pneumonia among intensive care unit patients in a suburban medical center. Crit Care Med 2003;31(5):1312-1317.

5. Kollef MH, Shapiro SD, Silver P, St John RE, Prentice D, Sauer S, et al. A randomized, controlled trial of protocol-directed versus physician-directed weaning from mechanical ventilation. Crit Care Med 1997;25(4):567-574.

6. American Association for Respiratory Care. Position statement: respiratory care scope of practice. Irving, TX: AARC; August 1987. Revised December 2010. http://www.aarc.org/resources/position statements/dop.html. Accessed January 4, 2013.

7. Kollef MH, Shapiro SD, Clinkscale D, Cracchiolo L, Clayton D, Wilner R, et al. The effect of respiratory therapist-initiated treatment protocols on patient outcomes and resource utilization. Chest 2000; 117(2):467-475.

8. Stoller JK. Respiratory therapist-driven protocols. Rationale and efficacy. West J Med 1997;167(6):408-410.

9. Zimmerman L. Respiratory therapist-driven protocols. West J Med 1997;167(6):440-441. 


\section{Respiratory Therapy Organizational Changes}

10. Guidelines for the management of adults with hospital-acquired, ventilator-associated, and healthcare-associated pneumonia. Am J Respir Crit Care Med 2005;171(4):388-416.

11. Haupt MT, Bekes CE, Brilli RJ, Carl LC, Gray AW, Jastremski MS, et al. Guidelines on critical care services and personnel: recommendations based on a system of categorization of three levels of care. Crit Care Med 2003;31(11):2677-2683.

12. Netzer G, Liu X, Shanholtz C, Harris A, Verceles A, Iwashyna TJ. Decreased mortality resulting from a multicomponent intervention in a tertiary care medical intensive care unit. Crit Care Med 2011;39(2): 284-293.

13. Shadish WR, Cook TD, Campbell DT. Experimental and quasiexperimental designs for generalized causal inference. Boston: Houghton Mifflin; 2002.

14. Harris AD, Bradham DD, Baumgarten M, Zuckerman IH, Fink JC, Perencevich EN. The use and interpretation of quasi-experimental studies in infectious diseases. Clin Infect Dis 2004;38(11):15861591.

15. Netzer G, Liu X, Shanholtz C, Harris A, Verceles A, Iwashyna TJ. Decreased mortality resulting from a multicomponent intervention in a tertiary care medical intensive care unit. Crit Care Med 2011;39(2): 284-293.

16. Harris AD, Carmeli Y, Samore MH, Kaye KS, Perencevich E. Impact of severity of illness bias and control group misclassification bias in case-control studies of antimicrobial-resistant organisms. Infect Control Hosp Epidemiol 2005;26(4):342-345.

17. Furuno JP, Perencevich EN, Johnson JA, Wright MO, McGregor JC, Morris JG Jr, et al. Methicillin-resistant Staphylococcus aureus and vancomycin-resistant Enterococci co-colonization. Emerg Infect Dis 2005;11(10):1539-1544.

18. McDonald JR, Engemann JJ, Kaye KS, Sexton DJ. Co-infection or co-colonization with vancomycin-resistant Enterococci and methicillin-resistant Staphylococcus aureus in a network of community hospitals. Infect Control Hosp Epidemiol 2004;25(8):622.

19. Harris AD, Nemoy L, Johnson JA, Martin-Carnahan A, Smith DL, Standiford H, et al. Co-carriage rates of vancomycin-resistant Enterococcus and extended-spectrum beta-lactamase-producing bacteria among a cohort of intensive care unit patients: implications for an active surveillance program. Infect Control Hosp Epidemiol 2004; 25(2):105-108.

20. Harris AD, Perencevich E, Roghmann MC, Morris G, Kaye KS, Johnson JA. Risk factors for piperacillin-tazobactam-resistant Pseudomonas aeruginosa among hospitalized patients. Antimicrob Agents Chemother 2002;46(3):854-858

21. Harris AD, Smith D, Johnson JA, Bradham DD, Roghmann MC. Risk factors for imipenem-resistant Pseudomonas aeruginosa among hospitalized patients. Clin Infect Dis 2002;34(3):340-345.

22. The Maryland Health Services Cost Review Commission. Case mix measurement. http://www.hscrc.state.md.us/hsp_Rates4.cfm. Accessed January 4, 2013.

23. Rosner B. Fundamentals of biostatistics. Belmont, CA: Duxbury Press; 1995

24. Fleiss JL. Statistical methods for rates and proportions. New York: Wiley; 1981.

25. Mann H, Whitney D. On a test of whether one of two random variables is stochastically larger than the other. Ann Mathemat Stat 1947; 18:50-60

26. Fisher R. The design of experiments. Edinburgh: Oliver and Boyd; 1953.

27. Mathews P, Drumheller L, Carlow JJ. Respiratory care manpower issues. Crit Care Med 2006;34(3 Suppl):S32-S45.

28. MacIntyre NR, Cook DJ, Ely EW Jr, Epstein SK, Fink JB, Heffner $\mathrm{JE}$, et al. Evidence-based guidelines for weaning and discontinuing ventilatory support: a collective task force facilitated by the Amer- ican College of Chest Physicians; the American Association for Respiratory Care; and the American College of Critical Care Medicine. Chest 2001;120(6 Suppl):375S-395S.

29. Ely EW, Baker AM, Dunagan DP, Burke HL, Smith AC, Kelly PT, et al. Effect on the duration of mechanical ventilation of identifying patients capable of breathing spontaneously. N Engl J Med 1996; 335(25):1864-1869.

30. Ely EW, Meade MO, Haponik EF, Kollef MH, Cook DJ, Guyatt GH, et al. Mechanical ventilator weaning protocols driven by nonphysician health-care professionals: evidence-based clinical practice guidelines. Chest 2001;120(6 Suppl):454S-463S.

31. Ely EW, Bennett PA, Bowton DL, Murphy SM, Florance AM, Haponik EF. Large scale implementation of a respiratory therapistdriven protocol for ventilator weaning. Am J Respir Crit Care Med 1999;159(2):439-446.

32. Scheinhorn DJ, Chao DC, Stearn-Hassenpflug M, Wallace WA. Outcomes in post-ICU mechanical ventilation: a therapist-implemented weaning protocol. Chest 2001;119(1):236-242.

33. Robertson TE, Sona C, Schallom L, Buckles M, Cracchiolo L, Schuerer D, et al. Improved extubation rates and earlier liberation from mechanical ventilation with implementation of a daily spontaneous-breathing trial protocol. J Am Coll Surg 2008;206(3):489-495.

34. Esteban A, Frutos F, Tobin MJ, Alía I, Solsona JF, Valverdú I, et al A comparison of four methods of weaning patients from mechanical ventilation. Spanish Lung Failure Collaborative Group. N Engl J Med 1995;332(6):345-350.

35. Girard TD, Kress JP, Fuchs BD, Thomason JW, Schweickert WD, Pun BT, et al. Efficacy and safety of a paired sedation and ventilator weaning protocol for mechanically ventilated patients in intensive care (Awakening and Breathing Controlled trial): a randomised controlled trial. Lancet 2008;371(9607):126-134.

36. Hooper MH, Girard TD. Sedation and weaning from mechanical ventilation: linking spontaneous awakening trials and spontaneous breathing trials to improve patient outcomes. Crit Care Clin 2009; 25(3):515-525, viii.

37. Singh N, Rogers P, Atwood CW, Wagener MM, Yu VL. Shortcourse empiric antibiotic therapy for patients with pulmonary infiltrates in the intensive care unit. A proposed solution for indiscriminate antibiotic prescription. Am J Respir Crit Care Med 2000;162 (2 Pt 1):505-511.

38. Brun-Buisson C, Fartoukh M, Lechapt E, Honore S, Zahar JR, Cerf $\mathrm{C}$, et al. Contribution of blinded, protected quantitative specimens to the diagnostic and therapeutic management of ventilator-associated pneumonia. Chest 2005;128(2):533-544.

39. Fagon JY, Chastre J, Wolff M, Gervais C, Parer-Aubas S, Stephan F, et al. Invasive and noninvasive strategies for management of suspected ventilator-associated pneumonia. A randomized trial. Ann Intern Med 2000;132(8):621-630.

40. Kim MM, Barnato AE, Angus DC, Fleisher LA, Kahn JM. The effect of multidisciplinary care teams on intensive care unit mortality. Arch Intern Med 2010;170(4):369-376.

41. Pronovost PJ, Angus DC, Dorman T, Robinson KA, Dremsizov TT, Young TL. Physician staffing patterns and clinical outcomes in critically ill patients: a systematic review. JAMA 2002;288(17): 2151-2162.

42. Mazzocco MC, Owens GR, Kirilloff LH, Rogers RM. Chest percussion and postural drainage in patients with bronchiectasis. Chest 1985;88(3):360-363

43. Hill K, Patman S, Brooks D. Effect of airway clearance techniques in patients experiencing an acute exacerbation of chronic obstructive pulmonary disease: a systematic review. Chron Respir Dis 2010; 7(1):9-17. 


\section{Respiratory Therapy Organizational Changes}

44. Wollmer P, Ursing K, Midgren B, Eriksson L. Inefficiency of chest percussion in the physical therapy of chronic bronchitis. Eur J Respir Dis 1985;66(4):233-239.

45. Overend TJ, Anderson CM, Lucy SD, Bhatia C, Jonsson BI, Timmermans $\mathrm{C}$. The effect of incentive spirometry on postoperative pulmonary complications: a systematic review. Chest 2001;120(3): 971-978.

46. O'Donohue WJ, Jr. National survey of the usage of lung expansion modalities for the prevention and treatment of postoperative atelec- tasis following abdominal and thoracic surgery. Chest 1985;87(1): 76-80.

47. Lawrence VA, Cornell JE, Smetana GW. Strategies to reduce postoperative pulmonary complications after noncardiothoracic surgery: systematic review for the American College of Physicians. Ann Intern Med 2006;144(8):596-608.

48. Raoof S, Goulet K, Esan A, Hess DR, Sessler CN. Severe hypoxemic respiratory failure. Part 2: nonventilatory strategies. Chest 2010;137(6):1437-1448.

This article is approved for Continuing Respiratory Care Education credit. For information and to obtain your CRCE

(free to AARC members) visit www.rcjournal.com 